\title{
Review
}

\section{Cardiovascular Pathophysiology, Epidemiology, and Treatment Considerations of Coronavirus Disease 2019 (COVID-19): A Review}

\author{
Jeremy Y. Levett, ${ }^{\mathrm{a}, \mathrm{b}}$ Valeria Raparelli, MD, PhD, ${ }^{\mathrm{c}}$ Vartan Mardigyan, MD, ${ }^{\mathrm{d}}$ and \\ Mark J. Eisenberg, MD, $\mathrm{MPH}^{\mathrm{a}, \mathrm{b}, \mathrm{d}, \mathrm{e}}$ \\ ${ }^{a}$ Center of Clinical Epidemiology, Lady Davis Institute, Jewish General Hospital/McGill University, Montreal, Quebec, Canada \\ ${ }^{b}$ Faculty of Medicine, McGill University, Montreal, Quebec, Canada \\ ${ }^{c}$ Department of Experimental Medicine, Sapienza University of Rome, Rome, Italy \\ ${ }^{d}$ Division of Cardiology, Jewish General Hospital/McGill University, Montreal, Quebec, Canada \\ ${ }^{e}$ Department of Epidemiology, Biostatistics and Occupational Health, McGill University, Montreal, Quebec, Canada
}

\begin{abstract}
The coronavirus disease 2019 (COVID-19) pandemic caused by the severe acute respiratory syndrome coronavirus 2 (SARS-CoV-2) is rapidly evolving, with important cardiovascular considerations. The presence of underlying cardiovascular risk factors and established cardiovascular disease (CVD) may affect the severity and clinical management of patients with COVID-19. We conducted a review of the literature to summarize the cardiovascular pathophysiology, risk factors, clinical presentations, and treatment considerations of COVID-19 patients with underlying CVD. Angiotensin-converting enzyme 2 (ACE2)
\end{abstract}

In late December 2019, a severe acute respiratory syndrome coronavirus 2 (SARS-CoV-2) outbreak occurred in Wuhan, China. ${ }^{1}$ The World Health Organization declared the coronavirus disease 2019 (COVID-19), caused by SARS-CoV-2, to be a public health emergency of international concern, which has since been characterized as a pandemic. ${ }^{2}$ Although COVID-19 patients present primarily with respiratory symptoms, reports are evolving of patients developing significant cardiovascular complications. ${ }^{3}$ Several studies have previously found a transient yet pronounced association between lower respiratory tract infections and acute coronary syndromes, suggesting important clinical implications of SARS-

Received for publication June 18, 2020. Accepted September 2, 2020.

Ethics Statement: The research reported has adhered to the relevant ethical guidelines.

Corresponding author: Dr Mark J. Eisenberg, Professor of Medicine, Divisions of Cardiology and Clinical Epidemiology, Jewish General Hospital, 3755 Côte Ste-Catherine Rd, Suite H-421.1, Montreal, Quebec, H3T 1E2, Canada. Tel.: +1-514-340-8222 x23564; fax: +1-514-340-7564.

E-mail: mark.eisenberg@mcgill.ca

See page 36 for disclosure information.

\section{RÉSUMÉ}

La pandémie de la maladie à coronavirus 2019 (COVID-19) causée par le coronavirus du syndrome respiratoire aigu sévère 2 (SRAS-CoV-2) évolue rapidement, et des considérations cardiovasculaires importantes y sont rattachées. La présence de facteurs de risque cardiovasculaire sous-jacents ou d'une maladie cardiovasculaire (MCV) établie peut influer la gravité de la COVID-19 et la prise en charge des patients qui en sont atteints. Nous avons effectué une revue de la littérature afin de résumé la physiopathologie cardiovasculaire, les facteurs de risque, les manifestations cliniques et les traitements à

CoV-2. ${ }^{4-7}$ This review elucidates the biological underpinnings for COVID-19's impact on the heart, epidemiologic trends related to cardiovascular disease (CVD), cardiovascular society guideline recommendations, and cardiovascular clinical implications characterized in the context of the COVID-19 pandemic. Summarizing and understanding the pathophysiological basis for these changes will have immediate implications for the clinical management of these patients, prove critical to the development of effective diseasemodifying treatments, and ultimately reduce mortality.

\section{Methodological Considerations}

We narratively reviewed the published literature (including searches in the MEDLINE [via PubMed] database) and grey literature from inception through May 18, 2020. Articles were retrieved using keywords and medical subject heading terms related to COVID-19, SARS-CoV-2, and the cardiovascular system. Observational studies and articles discussing the cardiovascular pathophysiology, epidemiology, and treatment considerations of COVID-19 were considered relevant for this narrative synthesis. Titles and abstracts were screened, and citations considered potentially eligible were retrieved for 
has been identified as a functional receptor for the SARS-CoV-2 virus, and it is associated with the cardiovascular system. Hypertension, diabetes, and CVD are the most common comorbidities in COVID-19 patients, and these factors have been associated with the progression and severity of COVID-19. However, elderly populations, who develop more-severe COVID-19 complications, are naturally exposed to these comorbidities, underscoring the possible confounding of age. Observational data support international cardiovascular societies' recommendations to not discontinue ACE inhibitor/angiotensinreceptor blocker therapy in patients with guideline indications for fear of the increased risk of SARS-CoV-2 infection, severe disease, or death. In addition to the cardiotoxicity of experimental antivirals and potential interactions of experimental therapies with cardiovascular drugs, several strategies for cardiovascular protection have been recommended in COVID-19 patients with underlying CVD. Troponin elevation is associated with increased risk of in-hospital mortality and adverse outcomes in patients with COVID-19. Cardiovascular care teams should have a high index of suspicion for fulminant myocarditislike presentations being SARS-CoV-2 positive, and remain vigilant for cardiovascular complications in COVID-19 patients. considérer pour les patients atteints de la COVID-19 et présentant une MCV sous-jacente. L'enzyme de conversion de l'angiotensine 2 (ECA2), qui intervient dans le système cardiovasculaire, a été identifiée comme étant un récepteur fonctionnel du SRAS-CoV-2. L'hypertension, le diabète et la MCV sont les affections concomitantes les plus fréquentes chez les patients atteints de la COVID-19, et ces facteurs ont été associés à l'évolution et à la gravité de la COVID-19. Les personnes âgées, chez qui les complications de la COVID-19 sont plus graves, sont cependant naturellement plus exposées à ces affections, ce qui fait ressortir l'âge comme étant un facteur de confusion possible. Les données d'observation soutiennent les recommandations des organismes internationaux s'intéressant à la santé cardiovasculaire, qui sont de ne pas cesser le traitement d'inhibiteur d'enzyme de conversion de l'angiotensine ou d'antagoniste des récepteurs de l'angiotensine lorsque ces traitements sont indiqués selon les lignes directrices, par crainte d'accroître le risque de maladie grave ou de décès pour les patients atteints par le SRAS-CoV-2. Compte tenu des effets cardiotoxiques des antiviraux expérimentaux et des interactions possibles entre les traitements expérimentaux et les médicaments utilisés pour traiter les MCV, plusieurs stratégies de protection cardiovasculaire ont été recommandées pour le traitement des patients atteints de la COVID-19 présentant une MCV sous-jacente. L'élévation de la troponine est associée à un risque accru de mortalité hospitalière et à des résultats défavorables pour les patients atteints de la COVID19. Les équipes de soins cardiovasculaires doivent toujours garder à l'esprit qu'un patient présentant des symptômes évocateurs d'une myocardite fulminante pourrait être infecté par le SRAS-CoV-2 et surveiller les complications cardiovasculaires chez les patients atteints de la COVID-19.

receptor-binding domains are structurally similar to those of SARS-CoV-1 (cause of the 2003 global SARS outbreak) and Middle Eastern Respiratory Syndrome Coronavirus (MERS$\mathrm{CoV}$ ) viruses. ${ }^{8}$ Seeing that SARS-CoV-1 uses an external spike subdomain to invade lung alveolar epithelial cells via the angiotensin-converting enzyme 2 (ACE2) surface protein, it has been suggested and proven that SARS-CoV-2 similarly uses ACE2 as a functional receptor (Fig. 1). ${ }^{8-10}$ The high ACE2 expression on lung pneumocytes, structural ligandreceptor interaction of SARS-CoV-2 and ACE2, and lower respiratory tract symptoms that accompany SARS-CoV-2 infection validate ACE2 as the site for SARS-CoV-2 entry and viral replication in humans. ${ }^{10,11}$ This finding has important clinical implications, given that ACE2 is also highly expressed in small intestine, heart, venous endothelial, and kidney tissues. ${ }^{11}$ ACE2 functions by degrading angiotensin II (converted by ACE1 from angiotensin I) into angiotensin 1-7 (Ang 1-7), in turn opposing the pressor response of angiotensin II and inducing a vasodilatory response. ${ }^{12}$

The elevated expression of several cardiovascular biomarkers has been reported in severe COVID-19 cases. $3,13-16$ These changes support involvement of the cardiovascular system, which can be explained by the combined effects of several mechanisms (Fig. 1). ${ }^{3,17}$ First, the systemic oxidative stress induced by hypoxemia in severe acute respiratory syndromes can directly damage cardiomyocytes, resulting in intracellular acidosis and mitochondrial damage. ${ }^{17,18}$ Second, ACE2 receptors also located in the cardiovascular system can dysregulate the renin-angiotensin-aldosterone (RAAS) system,

\section{Discussion/Observations}

\section{Pathophysiology}

\footnotetext{
A next-generation sequencing experiment of SARS-CoV-2
revealed that although genetically distinct, SARS-CoV-2 virus

A next-generation sequencing experiment of SARS-CoV-2
revealed that although genetically distinct, SARS-CoV-2 virus
}

full-text review. References of included articles were also searched for relevance, as were articles of major peer-reviewed
journals that were not yet indexed. The grey literature was searched for relevant clinical and epidemiologic information via major public health websites including the World Health for Disease Control and Prevention (CDC), as well as Epidaly). Extracted epidemiologic data included study (smoking, hypertension, diabetes, CVD, coronary artery cerebrovascular disease), and cardiovascular biomarker levels. Identified primary articles published by the inclusion date that comorbidities in COVID-19- positive (clinically diagnosed and/or confirmed by reverse-transcriptase polymerase chain Taction-positive testing) adult patients are included in and clinical trial registrations were excluded, as were studies that focused on patient subpopulations (eg, pediatric or included. If studies divided patients into cohorts, count data were pooled in Tables 1 and 2 to reflect all patients. 
Table 1. Cardiovascular clinical presentations of COVID-19 patients in identified observational studies in China

\begin{tabular}{|c|c|c|c|c|c|c|c|c|c|}
\hline Study & $\begin{array}{l}\text { Sample } \\
\text { size }(\mathrm{n})\end{array}$ & Location & $\begin{array}{l}\text { Median } \\
\text { age, y }\end{array}$ & Smoking* $\mathrm{n}(\%)$ & Hypertension, n (\%) & Diabetes, n (\%) & CVD, n (\%) & $\mathrm{CAD}, \mathrm{n}(\%)$ & $\begin{array}{c}\text { Cerebrovascular } \\
\text { disease, n }(\%)\end{array}$ \\
\hline Guan et al., $2020^{30}$ & 1099 & 30 provinces, China & 47.0 & $158(14.6)$ & $165(15.0)$ & $81(7.4)$ & - & $27(2.5)$ & $15(1.4)$ \\
\hline Shi et al., $2020^{45}$ & 416 & Hubei, China & 64.0 & - & $127(30.5)$ & $60(14.4)$ & - & $44(10.6)$ & $22(5.3)$ \\
\hline Wu et al., $2020^{34}$ & 201 & Hubei, China & 51.0 & - & $39(19.4)$ & $22(10.9)$ & $8(4.0)$ & - & - \\
\hline Zhou et al., $2020^{13}$ & 191 & Hubei, China & 56.0 & $11(5.8)$ & $58(30.0)$ & $36(18.9)$ & - & $15(7.9)$ & - \\
\hline Guo et al., $2020^{44}$ & 187 & Hubei, China & $58.5^{\dagger}$ & $18(9.6)$ & $61(32.6)$ & $28(15.0)$ & $66(35.3)$ & $21(11.2)$ & - \\
\hline Xie et al., $2020^{119, \ddagger}$ & 168 & Hubei, China & 70.0 & - & $84(50.0)$ & $42(25.0)$ & - & $31(18.5)$ & - \\
\hline Ruan et al., $2020^{15}$ & 150 & Hubei, China & 57.7 & - & $52(34.7)$ & $25(16.7)$ & $13(8.7)$ & - & $12(8.0)$ \\
\hline Zhang et al., $2020^{32}$ & 140 & Hubei, China & 57.0 & $9(6.4)$ & $42(30.0)$ & $17(12.1)$ & - & $7(5.0)$ & $3(2.1)$ \\
\hline Wang et al., $2020^{14}$ & 138 & Hubei, China & 56.0 & - & $43(31.2)$ & $14(10.1)$ & $20(14.5)$ & - & $7(5.1)$ \\
\hline Liu et al., $2020^{97}$ & 137 & Hubei, China & 57.0 & - & $13(9.5)$ & $14(10.2)$ & $10(7.3)$ & - & - \\
\hline Wei et al., $2020^{46}$ & 101 & Sichuan, China & $49.0^{\dagger}$ & $8(7.9)$ & $21(20.8)$ & $14(13.9)$ & - & $5(5.0)$ & $6(5.9)$ \\
\hline Chen et al., $2020^{31}$ & 99 & Hubei, China & $55.5^{\dagger}$ & - & - & $12(12.1)$ & $40(40.4)^{\S}$ & - & $40(40.4)^{\S}$ \\
\hline Yang et al., $2020^{43}$ & 52 & Hubei, China & $59.7^{\dagger}$ & $2(3.8)$ & - & $9(17.3)$ & $5(9.6)$ & 一 & $7(13.5)$ \\
\hline Huang et al., $2020^{3}$ & 41 & Hubei, China & 49.0 & $3(7.3)$ & $6(14.6)$ & $8(19.5)$ & $6(14.6)$ & 一 & - \\
\hline
\end{tabular}

Values are $\mathrm{n}(\%)$, unless otherwise indicated.

CAD, coronary artery disease; COVID-19, coronavirus disease 2019; CVD, cardiovascular disease.

* Current or former smoker.

${ }^{\dagger}$ Data reported as mean.

¥ This case series was of COVID-19 patients who died.

$\S$ This study pooled cardiovascular and cerebrovascular diseases when reporting baseline characteristics.

leading to altered myocardial demand via ventricular remodeling and further induction of cardiomyocyte damage. ${ }^{19,20}$ Third, the cytokine storm induced by the systemic inflammatory response syndrome to COVID-19 has been reported in autopsy findings to result in cardiac interstitial mononuclear inflammatory infiltrates. ${ }^{21-23}$ Finally, these local and systemic effects can induce cardiac microvasculature damage resulting in perfusion defects. In a case report of a COVID-19 patient with cardiogenic shock, endomyocardial biopsy identified viral particles of SARS-CoV-2. ${ }^{16}$ However, these particles were in the interstitial space, and no viral particles were identified within the cardiomyocytes. In addition, the biopsy showed a low grade of myocardial inflammation that was not proportional to the degree of left-ventricular dysfunction.

\section{Clinical presentation}

Cardiovascular epidemiology. Individuals with preexisting multi-morbidities and COVID-19 are reported to be at higher risk of adverse clinical outcomes. ${ }^{24}$ Of note, hypertension, diabetes, and CVD were consistently found to be the most common comorbidities in COVID-19 patients across all identified studies (Table 1). Even though these studies consistently reported correlations, age remains an important confounding variable. Older individuals with COVID-19 are known to suffer a more severe clinical course than younger individuals, and hypertension and diabetes are among the most common ccomorbidities in this population. Therefore, it is possible that these associations are confounded by age.

Table 2. Cardiovascular clinical presentations of hospitalized, critically ill, or fatal COVID-19 cases in identified observational studies primarily outside of China

\begin{tabular}{|c|c|c|c|c|c|c|c|c|c|}
\hline Study & $\begin{array}{l}\text { Sample } \\
\text { size }(\mathrm{n})\end{array}$ & Location & $\begin{array}{l}\text { Median } \\
\text { age, y }\end{array}$ & $\begin{array}{c}\text { Hypertension, } \\
\text { n (\%) }\end{array}$ & $\begin{array}{l}\text { Diabetes, } \\
\text { n (\%) }\end{array}$ & CVD, n (\%) & $\mathrm{CAD}, \mathrm{n}(\%)$ & $\begin{array}{c}\text { Atrial } \\
\text { fibrillation, } \\
\mathrm{n}(\%)\end{array}$ & $\begin{array}{c}\text { Congestive } \\
\text { heart failure, } \\
\text { n (\%) }\end{array}$ \\
\hline Richardson et al., $2020^{42, *}$ & 5700 & $\begin{array}{c}\text { New York City } \\
\text { area, USA }\end{array}$ & 63.0 & $3026(56.6)$ & $1808(33.8)$ & - & $595(11.1)$ & - & $371(6.9)$ \\
\hline $\begin{array}{l}\text { College of Health } \\
\text { et al., } 2020 \text { (originally } \\
\text { written (COVID-19 } \\
\text { Surveillance Group) } \\
37, \dagger\end{array}$ & 2848 & Italy & 81 & $1940(68.1)$ & $870(30.5)$ & - & $804(28.2)$ & $642(22.5)$ & $457(16.0)$ \\
\hline Grasselli et al., $2020^{38}$ & 1591 & Lombardy region, Italy & 63 & $509(49.0)$ & $180(17.0)$ & $223(21.0)^{\ddagger}$ & - & - & - \\
\hline Goyal et al., $2020^{40}, *$ & 393 & New York City, USA & 62 & $197(50.1)$ & $99(25.2)$ & - & $54(13.7)$ & - & $28(7.1)$ \\
\hline Myers et al., $2020^{41, *}$ & 377 & Northern California, USA & 61 & $164(43.5)$ & $118(31.3)$ & - & - & - & $22(5.8)$ \\
\hline Onder et al., $2020^{24, \dagger}$ & 355 & Italy & $79^{\S}$ & - & $72(20.3)$ & - & $117(30.0)$ & $87(24.5)$ & - \\
\hline Arentz et al., $2020^{39, \dagger}$ & 21 & Washington State, USA & $70^{\S}$ & - & $7(33.3)$ & - & - & - & $9(42.9)$ \\
\hline
\end{tabular}

Values are $\mathrm{n}(\%)$, unless otherwise indicated.

CAD, coronary artery disease; COVID-19, coronavirus disease 2019; CVD, cardiovascular disease; USA, United States of America.

* These case series were of hospitalized COVID-19 patients.

${ }^{\dagger}$ These case series were of COVID-19 patients with severe or fatal disease.

${ }^{\ddagger} \mathrm{CVD}$ includes cardiomyopathy and heart failure.

${ }^{\S}$ Data reported as mean. 


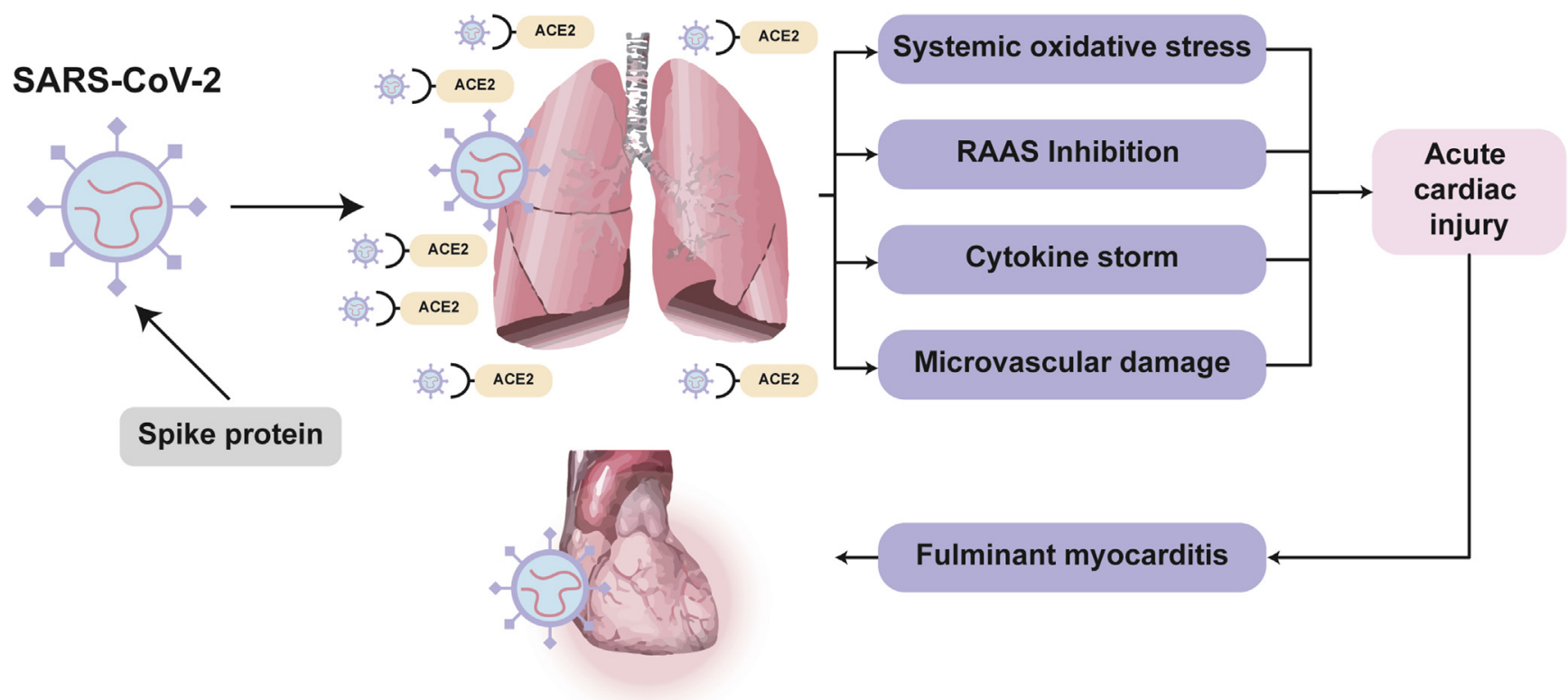

Figure 1. Hypothesized pathophysiological mechanisms of the systemic and cardiovascular interactions of SARS-CoV-2 and ACE2. ACE2, angiotensin-converting enzyme 2; RAAS, renin-angiotensin-aldosterone system; SARS-CoV-2, severe acute respiratory syndrome coronavirus 2.

The majority of early COVID-19 studies originate from China. An appreciation of the epidemiological landscape in China prior to the COVID-19 pandemic is important for comparing trends observed in the COVID-19 outbreak. Studies have previously characterized China as having an aging population, for whom atherosclerotic CVD is the leading cause of death, and the prevalence of hypertension and diabetes is $23.2 \%$ and $10.9 \%$, respectively. ${ }^{25-28}$ Furthermore, trends in smoking have been consistently high, with a 2013 estimated proportion of current smokers in China being $25.2 \% .{ }^{29}$ The leading causes of years of life lost in China are atherosclerotic CVD, lung cancer, chronic obstructive pulmonary disease, and liver cancer. ${ }^{28}$ Of the 14 identified observational studies from China, 8 reported on the prevalence of concomitant CVD in COVID-19 patients, which ranged between $4.0 \%$ and $40.4 \%$ (Table 1; the upper estimate combined CVD with cerebrovascular disease). The proportion of COVID-19 patients with underlying hypertension ranges between $9.5 \%$ and $50.0 \%$ (Table 1; the upper estimate is in fatal COVID-19 cases), and the proportion with comorbid diabetes ranges between $7.4 \%$ and $25.0 \%$. Furthermore, $3.8 \%-14.6 \%$ of COVID-19 patients are reported to have a smoking history. Finally, $2.5 \%-18.5 \%$ (upper estimate is in fatal COVID-19 cases) of COVID-19 patients are reported to have preexisting $\mathrm{CAD}$. Although these data greatly inform the clinical picture of COVID-19 patients in China, still unclear, due to wide and overlapping estimates, is whether CVD patients are disproportionately diagnosed with COVID-19.

Preexisting CVD and COVID-19 disease severity. Underlying cardiovascular risk factors and disease have been associated with the severity of COVID-19 progression and are closely related with age., ${ }^{3,1430-32}$ The population-wide serology-informed fatality risk for SARS-CoV-2 infection has been estimated at $0.64 \%$ (95\% credible interval: $0.38 \%$ $0.98 \%$ ), with older age groups contributing the vast majority of fatalities. ${ }^{33}$ Although intervals vary among studies, withinstudy data suggest that hypertension is a clinical condition associated with COVID-19 severity. ${ }^{3,14,15}$ In a bivariate Cox regression analysis, hypertension was associated with a significant $82 \%$ increased risk of development of acute respiratory distress syndrome (ARDS) in COVID-19 patients, compared with nonhypertensive COVID-19 patients (hazard ratio [HR]: 1.82; $95 \%$ confidence interval [CI]: 1.13-2.95). ${ }^{34}$ Similarly, diabetes was associated with a significant $134 \%$ increased risk of COVID-19 patients developing ARDS, compared with nondiabetic COVID-19 patients (HR: 2.34; 95\% CI: $1.35-$ 4.05 ), as well as a nonsignificant $58 \%$ increased risk in mortality (HR: 1.58 ; 95\% CI: $0.80-3.13$ ). ${ }^{34}$ Fang et al. propose that the increased expression of ACE2 seen in type I and II diabetics and the therapeutic administration of angiotensinconverting enzyme inhibitors (ACEis)/ angiotensin receptor blockers (ARBs) in hypertensive patients contribute to increased viral entry and COVID-19 disease severity. ${ }^{35}$ However, further studies are necessary, as these hypotheses are not yet clinically supported. The underlying microvascular disease in diabetes may also predispose COVID-19 diabetic patients to further microvascular damage and cardiac injury hypothesized to be induced by SARS-CoV-2. CAD has also been shown to have an increased prevalence in COVID-19 patients. $3,14,30-32$ In three studies, between 9\% and 25\% of COVID-19 patients admitted to the intensive care unit (ICU) had underlying CVD, whereas CVD was present in only $2 \%-11 \%$ of non-ICU patients. ${ }^{3,14,30}$ Although precise pathophysiological mechanisms are not yet described, these results suggest that underlying CVD should be considered in the prognostication and prioritization of treatment for COVID-19 patients. ${ }^{36}$

Baseline clinical data have also been published on severe COVID-19 patients, primarily outside of China, who were either hospitalized or critically ill, or who died (Table 2). Seven observational studies were identified, of which 3 reported data from Italy, ${ }^{24,37,38}$ and 4 from the United States 
(US; Table 2). ${ }^{39-42}$ Data reported by the COVID-19 Surveillance Group indicated that $68.1 \%$ (1940 of 2848) of COVID-19 nonsurvivors in Italy had underlying hypertension. ${ }^{37}$ Further data from Italy reported that the prevalence of atrial fibrillation ranged between $22.5 \%$ and $24.5 \%$ in COVID-19 patients who had died. ${ }^{24}$ In a US observational study of 5,700 hospitalized COVID-19 patients, hypertension $(56.6 \%)$, obesity $(41.7 \%)$, and diabetes $(33.8 \%)$ were the most common comorbidities. ${ }^{42}$ Hypertension was consistently found to be the most prevalent comorbidity in larger US studies (range: $43.5 \%-56.6 \%)^{40-42}$

Cardiovascular biomarkers and COVID-19 disease severity. Of the 21 primary studies identified, 11 reported data on elevated cardiovascular biomarkers in relation to COVID-19. . $13-15,39,41-46$ Of 3533 patients hospitalized with COVID-19 in the New York City area, 22.6\% had a troponin level above the test-specific upper limit of normal. ${ }^{42}$ Troponin $\mathrm{T}$ elevations were more likely in patients with underlying CVD (54.5\%) compared to those without CVD (13.2\%) and were also significantly associated with a poor clinical outcome. ${ }^{44}$ Cardiac troponin I levels, as determined by a high-sensitivity test (hs-cTnI), were consistently elevated among severely ill COVID-19 patients compared to nonseverely ill COVID-19 patients (median estimates range between 3.3 and $30.3 \mathrm{pg} / \mathrm{mL}$ for nonsurvivor $/ \mathrm{ICU}$ patients vs $3.0-5.1 \mathrm{pg} / \mathrm{mL}$ for survivors/non-ICU patients). Between $31 \%$ and $46 \%$ of nonsurvivors were above the hs-cTnI 99th percentile upper reference limit $(>28 \mathrm{pg} / \mathrm{mL})$ vs only $1 \%-4 \%$ in survivors. 3,13 One study found the mortality rate during hospitalization in COVID-19 patients with elevated troponin $\mathrm{T}$ (TnT) and underlying CVD to be $69.4 \% \cdot{ }^{44}$ In a univariate analysis, $\log$ hs-cTnT and $\log \mathrm{N}$-terminal-proB-type natriuretic peptide were found to be statistically significant independent predictors of progression to severe disease in COVID-19 patients. ${ }^{46}$ Several studies have also demonstrated a trend of increased creatine kinase (CK) levels in COVID-19 nonsurvivors vs survivors; however, these findings were nonsignificant in most cases. ${ }^{3,13-15}$ One study has demonstrated CK above $185 \mathrm{U} / \mathrm{L}$ to be significantly increased in nonsurvivors $(21 \%)$ vs survivors $(9 \% ; P=0.038) .^{13}$ Whereas $59 \%$ of nonsurvivors developed acute cardiac injury, this outcome occurred in only $1 \%$ of survivors $(P<$ $0.0001){ }^{13}$ Similarly, $52 \%$ of nonsurvivors developed heart failure compared with only $12 \%$ of survivors $(P<0.0001){ }^{13}$ Studies have shown that more-severe COVID-19 presentations had elevated D-dimer levels and prothrombin time, suggestive of a hypercoagulable state. ${ }^{3,13,14,30}$ These findings are consistent with the immune-mediated multisystem inflammatory syndrome associated with COVID-19, which has been documented in children and adolescents. ${ }^{47,48}$

\section{Treatment considerations}

Cardiovascular protection. Given that CVD patients are more likely to develop severe symptoms if infected with SARS-CoV-2, CVD patients will ultimately account for a large proportion of COVID-19 deaths. ${ }^{17}$ Trends are consistent with previous coronaviruses, ${ }^{49-51}$ suggesting that changes in clinical management should be implemented early in order to minimize the burden of CVD on systemic inflammatory responses. Aside from the systemic inflammatory demand created by COVID-19, the precise biological mechanisms of action of SARS-CoV-2 can theoretically contribute to increased cardiac vulnerability. It is possible that ACE2 sequestration by SARS-CoV-2, and the subsequent downregulation of its expression, ${ }^{52}$ may result in a depletion of the cardioprotective effects of Ang 1-7, for which ACE2 is responsible.

Statins have been suggested as a potential mechanism for cardiovascular protection, especially in COVID-19 patients with underlying CVD, as many may already have poor functional reserve and can rapidly deteriorate when confronting the higher metabolic demands of a viral infection such as SARS-CoV-2. In addition to regulating dyslipidemias, statins have been recognized for their antiinflammatory, immunomodulatory, and antithrombotic activity in patients with viral respiratory illnesses. ${ }^{53,54}$ Randomized controlled trial (RCT) data are conflicting on the use of statins in ventilator-associated pneumonia. ${ }^{55,56}$ However, beta coronaviruses highly induce the myeloid differentiation primary response 88 (MYD88) signaling pathway, and statins are known stabilizers of this pathway during hypoxia, promoting the innate immune response. $^{57,58}$ Especially in COVID-19 patients with underlying primary indications, statin therapy should not be discontinued and should be considered for cardiovascular protection in all COVID-19 patients. ${ }^{53}$

ACEi/ARB controversy. The continued use of ACEis and ARBs in patients with CVD and COVID-19 has been met with controversy. ${ }^{35,59,60}$ RAAS antagonists act on ACE2 by increasing its cell surface expression, which could theoretically contribute to increased viral entry; however, this effect has been demonstrated only in animal models. ${ }^{61,62}$ Counterintuitively, maintenance of normal ACE2 levels has protective pulmonary effects and is necessary for combatting inflammatory lung disease. ${ }^{63,64}$ The position of all major cardiovascular societies has been to continue ACEis/ ARBs in all COVID-19 patients who already have been prescribed these medications for indications such as hypertension, CAD, and heart failure (Table 3). ${ }^{65-70}$ This approach is consistent with an expert review on the interplay between SARS-CoV-2 and the RAAS system, which highlights insufficient clinical data and potentially beneficial effects during lung injury. ${ }^{64}$ Several large observational studies have since been published reporting that despite the more frequent use of ACEis/ARBs in COVID-19 patients, due to underlying CVD, there was no association between ACEi/ARB use and the risk of SARS-CoV-2 infection, COVID-19 clinical severity, or in-hospital mortality among those with a positive SARS-CoV-2 test. ${ }^{71-75}$ Although these observational studies are limited by unmeasured confounding, there is reassurance in the consistency of findings being independently published. RCTs will ultimately be necessary to definitively address these concerns, with several currently underway. ${ }^{76,77}$ Other drugs, such as thiazolidinediones and ibuprofen, have also been suggested to increase ACE2 expression, but reports are limited and unconvincing. ${ }^{35}$ 
Table 3. Cardiovascular Society recommendations on RAAS antagonists in the COVID-19 patient

\begin{tabular}{|c|c|c|}
\hline Society & Date of recommendation & RAAS antagonists recommendation \\
\hline$\overline{\mathrm{AHA} / \mathrm{HFSA} / \mathrm{ACC}^{65}}$ & March 17, 2020 & $\begin{array}{l}\text { - Continuation of ACEis/ARBs in COVID-19 patients with } \\
\text { preexisting indications (heart failure, hypertension, CAD) } \\
\text { - Careful consideration prior to addition/discontinuation of any } \\
\text { CVD treatments in COVID-19 patients }\end{array}$ \\
\hline Canadian Cardiovascular Society ${ }^{66}$ & March 20, 2020 & $\begin{array}{l}\text { - Continuation of ACEi/ARB/ARNi unless clinically contraindicated } \\
\text { (symptomatic hypotension, shock, AKI, hyperkalemia) }\end{array}$ \\
\hline ESC Council on Hypertension ${ }^{67}$ & March 13, 2020 & - Continue antihypertensive treatment \\
\hline European Society of Hypertension ${ }^{69}$ & April 15, 2020 & $\begin{array}{l}\text { - Stable COVID-19 patients should continue ACEi/ARB treatment } \\
\text { according to } 2018 \text { ESC/ESH guidelines } \\
\text { - Assess COVID-19 patients with severe symptoms, sepsis, or } \\
\text { hemodynamic instability on a case-by-case basis for the } \\
\text { discontinuation of blood pressure-lowering drugs, with } \\
\text { consideration for current guidelines }\end{array}$ \\
\hline Hypertension Canada $^{68}$ & March 13, 2020 & - Continue antihypertensive treatment \\
\hline $\begin{array}{l}\text { International Society of } \\
\text { Hypertension }^{70}\end{array}$ & March 16, 2020 & $\begin{array}{l}\text { - Routine use of ACEis/ARBs in hypertensive patients despite } \\
\text { COVID-19 concerns }\end{array}$ \\
\hline
\end{tabular}

ACC, American College of Cardiology; ACEi, angiotensin-converting enzyme inhibitor; AHA, American Heart Association; AKI, acute kidney injury; ARB, angiotensin-receptor blocker; ARNi, angiotensin receptor-neprilysin inhibitor; CAD, coronary artery disease; COVID-19, coronavirus disease 2019; ESC, European Society of Cardiology; ESH, European Society of Hypertension; HFSA, Heart Failure Society of America; RAAS, renin-angiotensin-aldosterone system.

Potential antiviral interactions with the cardiovascular system. The Liverpool Drug Interactions Group has developed a comprehensive evidence evaluation system synthesizing the drug-drug interactions of experimental COVID-19 therapies, which we have adapted specifically for cardiovascular drugs (Table 4). ${ }^{78}$ These interactions, combined with the increased cardiometabolic demand of COVID-19 patients, can precipitate cardiovascular complications. Cardiovascular care teams should be aware of important drug interactions as the urgent development of COVID-19 disease-modifying treatments further evolves.

Several antivirals being evaluated for the treatment of COVID-19 can adversely interact with cardiovascular drugs, and can induce myocardial toxicity, causing or exacerbating existing heart failure. ${ }^{78-80}$ Although observational studies suggest that they are not effective, and no randomized data supports their efficacy in COVID-19 patients, hydroxychloroquine and chloroquine are antimalarials that have been proposed for the treatment of COVID-19. ${ }^{81,82}$ These drugs have known cardiotoxic manifestations, such as corrected QT (QTc) interval prolongation, restrictive or dilated cardiomyopathy, and conduction system abnormalities, including atrioventricular and bundle-branch block. $^{79,80,83-85}$ In a phase IIb RCT of high- vs lowdosage chloroquine in severe COVID-19 patients, higherdosage chloroquine, especially when taken concurrently with azithromycin and oseltamivir, was found to be unsafe due to increased instances of QTc intervals greater than 500 $\mathrm{ms} .{ }^{86}$ In the high-dosage group, 2 of 37 patients experienced ventricular tachycardia without torsade de pointes, which is usually facilitated by a prolonged QTc interval, before death. ${ }^{86}$ In another cohort study of 84 consecutive COVID19 patients to whom hydroxychloroquine was administered with azithromycin orally, the QTc interval was significantly prolonged when compared to baseline. ${ }^{87}$ Several observational studies have described an increased risk of QTc interval prolongation in COVID-19 patients treated with hydroxychloroquine and azithromycin, compared to hydroxychloroquine alone. ${ }^{88,89}$ Drug-induced cardiotoxicity may be influenced by disease severity, age, and presence of comorbidities. ${ }^{87,90}$
Remdesivir, a nucleoside analogue prodrug that inhibits RNA-dependent RNA polymerases, has garnered much attention as a promising antiviral for the treatment of COVID-19. ${ }^{91,92}$ In the National Institutes of Health Adaptive COVID-19 Treatment Trial, hospitalized COVID-19 patients receiving remdesivir had a $31 \%$ faster recovery time than similar patients who received placebo $(P<0.001) .^{93}$ This finding is in contrast to that from a smaller RCT from China, which reported that remdesivir was not associated with decreased mortality or significant clinical benefit. ${ }^{94}$ Remdesivir has not been characterized as having an attributable cardiovascular side effect profile, although data are still lacking. Additionally, remdesivir has no known cardiovascular drugdrug interactions aside from a potential interaction with bosentan, which may require a dose adjustment or close monitoring. ${ }^{78}$ Dexamethasone, the first treatment to reduce COVID-19-related mortality in critically ill patients, ${ }^{95}$ has several potential interactions with antiarrhythmic, anticoagulant, antiplatelet, fibrinolytic, and hypertensive diuretic agents. ${ }^{78}$ The combination of lopinavir-ritonavir has also been proposed; however, in patients with CVD, these should be carefully considered, due to known QT prolongation effects and limited clinical benefit. ${ }^{96}$ Furthermore, this antiviral combination has several drug interactions, and can reduce the effectiveness of clopidogrel and oral anticoagulants (Table 4). ${ }^{96}$

Cardiac and intravascular injury. The cumulative cardiomyocyte damage and membrane disruption caused by the cardiovascular injury mechanisms elucidated may result in increased levels of hscTn1, CK, and creatine kinase myocardial band, as well as potential structural remodeling and enlargement observed on chest radiographs, electrocardiograms, and echocardiography. ${ }^{3,13-15}$ An early study described palpitations among the presenting complaints of COVID-19 patients. ${ }^{97}$ Electrocardiogram findings of cardiac arrhythmias have since been reported and include temporary S1Q3T3 patterns, atrioventricular block, and ST-segment elevation. ${ }^{98}$ Throughout the course of disease, malignant arrhythmias including multifocal ventricular tachycardia/ventricular fibrillation have been reported to develop and were associated 
Table 4. Summary of current COVID-19 experimental therapies and adverse cardiovascular drug interactions*

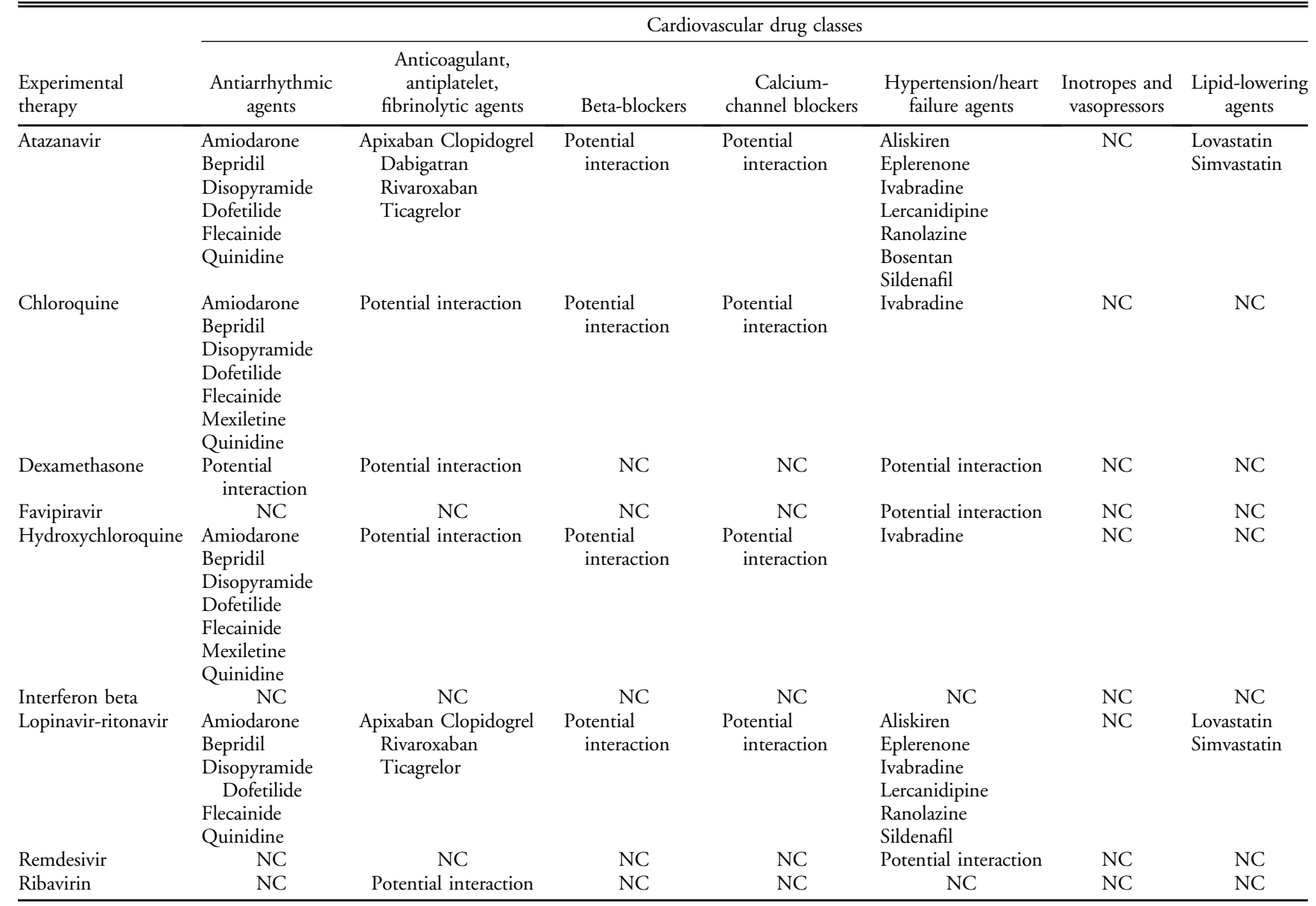

COVID-19, coronavirus disease 2019; NC, no clinically significant interaction.

${ }^{*}$ All information was adapted from the Liverpool Drug Interactions Group (July 13, 2020 version). ${ }^{78}$ Only drugs with strong recommendations against being coadministered were listed; however, classes with listed drugs could also have potential interactions. "Potential interaction" was used to report drug classes in which at least one drug interaction was expected to require a dose adjustment or additional monitoring. Potential interactions of weak intensity were considered similar to NC. For complete information, visit: Detailed recommendations for interactions with experimental COVID-19 antiviral therapies, July 13, 2020, University of Liverpool, available at www.covid19-druginteractions.org, accessed July 21, 2020.

with higher troponin T levels. ${ }^{44}$ Myocardial injury defined as troponin elevation can be due to target organ damage by hypoxemia, Takotsubo cardiomyopathy, or myocarditis, ${ }^{9}$ suggesting that myocardial injury may play a role in the fatality of some COVID-19 patients.

Furthermore, elevated D-dimer and prothrombin levels indicate a hypercoagulable state that has been associated with poor outcomes in COVID-19 patients. ${ }^{3,13,14,30}$ Especially in those with underlying CVD, the risks for hemodynamic changes from ischemia and thrombosis that result from this hypercoagulable state are of important clinical concern. ${ }^{13} \mathrm{~A}$ case series of young COVID-19 patients presenting with large-vessel stroke has been reported, further supporting coagulopathy and vascular endothelial dysfunction as complications of COVID-19. ${ }^{100}$ Critically ill COVID-19 patients may develop sepsis-induced coagulopathy or disseminated intravascular coagulation, warranting thromboembolic prophylaxis and standard supportive care measures. ${ }^{101}$ The International Society on Thrombosis and Haemostasis interim guidance on coagulopathy in COVID-19 recommends monitoring of fibrinogen in addition to other coagulation markers (platelet count, prothrombin time, and D-dimers) for critically ill patients with COVID-19. ${ }^{102}$ In a retrospective Chinese cohort of severe COVID-19 patients with markedly elevated D-dimer levels or meeting sepsis-induced coagulopathy criteria, anticoagulant therapy (mainly low-molecularweight heparin) appeared to be associated with decreased mortality. ${ }^{103}$ In an observational study of 2773 hospitalized COVID-19 patients, systemic anticoagulant therapy was suggested to be associated with improved outcomes; however, an individualized risk assessment must be made with consideration for bleeding events. ${ }^{104}$

Fulminant myocarditis. In some cases, the acute cardiac injury caused by SARS-CoV-2 infection can result in fulminant myocarditis, a rare clinical syndrome with hemodynamic compromise and high mortality rates ranging between $40 \%$ and $70 \%$ (Fig. 1). ${ }^{105}$ Fulminant myocarditis is characterized by sudden and diffuse cardiac inflammation, necrosis, and eventual ventricular dysfunction resulting in cardiogenic shock, malignant arrhythmias, multiorgan failure, and ultimately death. ${ }^{106}$ In the context of COVID-19, several 
pathophysiological mechanisms have been proposed to explain cardiac inflammation-the systemic exaggerated inflammatory effects caused by COVID-19 (Fig. 1), and the hypothesized direct SARS-CoV-2 viral entry via ACE2 receptors in the heart. ${ }^{17,105}$ Although endomyocardial biopsy localized SARS-CoV-2 in a patient with cardiogenic shock, pathologic findings demonstrated low-grade myocardial inflammation and absence of cardiomyocyte necrosis. ${ }^{16}$ In some cases, this clinical presentation requires urgent initiation of circulatory support, either in the form of inotropic agents or mechanical circulatory support, in order to sustain end-organ function. On the basis of elevated troponin $\mathrm{T}$ levels, mortality was markedly higher in patients with myocardial injury compared to those with normal troponin $\mathrm{T}$ levels $(59.6 \%$ vs $8.9 \%$, respectively). ${ }^{44,106}$

An illustrative case report recently documented that despite normal chest radiographs and minimal respiratory involvement throughout the clinical course, an otherwise healthy 53-year-old COVID-19 patient developed acute perimyocarditis. ${ }^{107}$ This patient was hypotensive, showed diffuse ST elevation on electrocardiography, and had elevated hs-cTnT and NT-proBNP levels. Cardiac magnetic resonance findings showed a circumferential pericardial effusion, severe left-ventricular dysfunction (left-ventricular ejection fraction of $35 \%$ ), and increased wall thickness with diffuse biventricular hypokinesis, all indicative of an acute perimyocarditis. Similar cases have been anecdotally reported, suggesting that fulminant myocarditis without overt respiratory manifestations of COVID-19 is possible. Although there are case reports of pericardial effusion and pericarditis in COVID-19 nasopharyngeal swab specimen-positive patients, ${ }^{108,109}$ it is unclear whether the virus has a causal role in this context. In fact, in one case, the serosanguinous pericardial fluid was drained and tested negative for SARS-CoV-2. ${ }^{109}$ This mechanism may be related to a postcardiac injury syndrome. The diagnosis of fulminant myocarditis should have a high index of suspicion if there is a marked elevation of troponins or a new onset of atrioventricular block or QRS prolongation. This suspicion is especially relevant in patients that are candidates for mechanical circulatory support.

In COVID-19 patients in whom hemodynamic shock has already ensued, numerous strategies for reestablishing hemodynamic stability exist, including inotropic agents, and mechanical life support such as intra-aortic balloon pumps, Impella devices, and ultimately extracorporeal membrane oxygenation (ECMO). The typical clinical course is a rapidly degenerating COVID-19 patient in respiratory distress, hypotension, and cardiogenic shock, who is then treated with mechanical ventilation and venous-venous or venousarterial ECMO as a bridge to recovery. ${ }^{16,110}$ This cardiovascular collapse clinically mimics fulminant myocarditis prompted by numerous pathophysiological factors (Fig. 1). ${ }^{16}$ Concerns have been raised regarding the limited therapeutic and resource-intensive use of ECMO. ${ }^{111,112}$ Although studies have reported poorer outcomes for COVID-19 patients on ECMO, this is likely due to the severity of the underlying disease, which initially predisposes this patient group to an overall lower chance of recovery. ${ }^{13,14}$ Furthermore, the prolonged period of ECMO use, which will likely be necessary in ARDS patients, increases the risks of ECMO-related complications, including bleeding, and renal, vascular, and infectious injuries. The resource-intensive use of ECMO is also an important consideration as ICUs reach capacity throughout the COVID-19 pandemic. ECMO for 2019 novel coronavirus acute respiratory disease (ECMOCard) is a prospective multicentre short-period incidence observational study currently recruiting patients that is aiming to describe the clinical features, disease severity, ECMO-related characteristics, complications, and survival of ICU patients with COVID-19. ${ }^{113}$

Acute coronary syndromes in COVID-19 patients. In SARS-CoV-2-positive or suspected patients, the recommendation of major cardiovascular societies is to pursue coronary angiography and primary percutaneous coronary intervention for ST-segment elevation myocardial infarction (STEMI) with aerosol-level precautions. Adequate infection control is advised due to the increased risks of viral aerosolization during urgent intubation, suctioning, or cardiopulmonary resuscitation, especially considering that the vast majority of cardiac catheterization laboratories are not negative-pressure ventilated. ${ }^{15,114}$ Fibrinolysis has also been controversially suggested as an alternative in relatively stable STEMI patients, in the event that the treating team does not have adequate infection control or access to rapid nucleic acid testing. ${ }^{115}$

However, in COVID-19 patients presenting with elevated hs-cTn1 or creatine kinase myocardial band and no STsegment elevations (NSTEMI), a high index of suspicion should be maintained for the possibility of myocarditis. ${ }^{114}$ In fact, in a recent case series, 10 of 18 COVID-19 patients presenting with ST-segment elevations were diagnosed with noncoronary myocardial injury as opposed to a myocardial infarction. ${ }^{116}$ Only 4 of these patients had diffuse ST-segment elevations. $^{116}$ Despite focal ST-segment elevations being a shared characteristic among all clinically diagnosed myocardial infarctions, 6 of the 10 noncoronary myocardial injuries also had only focal ST-segment elevations. ${ }^{116}$ Although diffuse ST-segment elevations in the absence of reciprocal changes is usually suggestive of a myocarditis, these findings are not ubiquitous. Clinical suspicion for noncoronary myocardial injury should therefore be maintained even if focal STsegment elevation on electrocardiographic findings of COVID-19 patients are present. Despite variability in presentation, the 8 patients clinically diagnosed with a myocardial infarction had higher median peak troponin and D-dimer levels than the noncoronary myocardial injury patients. ${ }^{116}$ In an effort to mitigate nosocomial infection risk, noninvasive testing such as coronary computed-tomography angiography or myocardial perfusion imaging tests could be considered for otherwise stable NSTEMI patients. ${ }^{114}$ If no underlying CAD is confirmed, these patients should be managed medically, avoiding the risk of aerosol-generating procedures in the cardiac catheterization laboratory. Predetermined resuscitation plans should be organized for patients anticipated to develop acute cardiac injury from COVID-19, and careful monitoring of electrocardiographic changes and cardiovascular and inflammatory biomarkers should guide management throughout hemodynamic recovery. ${ }^{114}$

Cardiovascular care teams will need to develop variable responses based on regional penetrance and healthcare systems capacity in order to balance COVID-19-related and routine cardiovascular care. Telehealth patient consultations and 
follow-ups are rapidly being adopted in order to triage for urgent care, address symptom control, and monitor medical management of CVD patients. ${ }^{36}$ However, care-seeking behavior and infection control measures due to the COVID-19 pandemic are expected to substantially disrupt healthcare systems and affect patient time to medical contact. The impact of the COVID-19 pandemic has already been reported to significantly increase time components of STEMI care, resulting in delayed time from symptom onset to first medical contact, as well as door-to-balloon time. ${ }^{117}$

\section{Limitations}

Although our findings are of significant clinical relevance, several important limitations must be considered. First, while a systematic attempt to summarize the literature was made, our review was not systematic, increasing the possibility for selection and publication biases. Due to the rapidly evolving nature of the COVID-19 pandemic, it would not be feasible to systematically review the literature, as studies containing critical information are being updated rapidly based on government reporting, are being published in real-time, and are not yet indexed in bibliographic databases. Furthermore, data were not quantitatively analyzed due to concerns of overlapping patient populations among reports. ${ }^{118}$ Second, our review included only articles published in English, which introduces a potential language bias. The COVID-19 pandemic has affected nearly every country worldwide, resulting in extensive research efforts and data reporting in native languages. Our interpretation of the latest clinical picture is limited to studies published in English language. Finally, the associations and clinical characteristics identified in this review are primarily correlative, and await clearly proven causative mechanisms. Important confounders exist in the crosssectional studies reviewed, including age, medications taken for CVD, and immune strength. In light of the extraordinary and unprecedented time pressure to report such urgent findings, the studies cited in this review were not necessarily operationalized in a systematic or multicentre manner, limiting the overall generalizability of their findings. This limitation is underscored by the in-between study variability in the prevalence rates reported. Larger case-controlled studies that account for these confounding variables will provide necessary insight on the precise risk factors of COVID-19 severity.

\section{Conclusions}

The COVID-19 pandemic is rapidly evolving, with important cardiovascular considerations. This review synthesizes the cardiovascular implications of COVID-19 and comprehensively addresses large international primary data on the cardiovascular epidemiology and treatment considerations of COVID-19. Hypertension, diabetes, and CVD are the most common comorbidities in COVID-19 patients, and these factors have been associated with the progression and severity of COVID-19. However, elderly populations, which develop more-severe COVID-19 complications, are naturally exposed to these comorbidities, underscoring the possible confounding of age. Observational data support international cardiovascular societies' recommendation to not discontinue ACEi/ARB therapy in patients with guideline indications out of fear for the increased risk of SARS-CoV-2 infection, severe disease, or death. In addition to the cardiotoxicity of experimental antivirals and the potential interactions of experimental therapies with cardiovascular drugs, several strategies for cardiovascular protection have been recommended in COVID-19 patients with underlying CVD. Troponin elevation is associated with increased risk of inhospital mortality and adverse outcomes in patients with COVID-19. Cardiovascular care teams should have a high index of suspicion for fulminant myocarditis-like presentations being SARS-CoV-2 positive, and remain vigilant for cardiovascular complications in COVID-19 patients.

\section{Funding Sources}

Mr Levett is supported by a Dr Clarke K. McLeod Memorial Scholarship, funded through the Research Bursary Program of the Faculty of Medicine of McGill University. Dr Raparelli is supported by the Scientific Independence of Young Researchers Program (RBSI14HNVT), Italian Ministry of Education, University and Research (MIUR), Rome, Italy. The other authors have no funding sources to declare.

\section{Disclosures}

The authors have no relevant conflicts of interest to disclose.

\section{References}

1. World Health Organization. Novel coronavirus-China. Available at: https://www.who.int/csr/don/12-january-2020-novel-coronavirus-chin a/en/. Accessed March 19, 2020.

2. World Health Organization. Coronavirus disease (COVID-19) outbreak. Available at: https://www.who.int/westernpacific/ emergencies/covid-19\#. Accessed March 18, 2020.

3. Huang C, Wang Y, Li X, et al. Clinical features of patients infected with 2019 novel coronavirus in Wuhan, China. Lancet 2020;395:497-506.

4. Smeeth L, Thomas SL, Hall AJ, et al. Risk of myocardial infarction and stroke after acute infection or vaccination. N Engl J Med 2004;351: 2611-8.

5. Cowan LT, Lutsey PL, Pankow JS, et al. Inpatient and outpatient infection as a trigger of cardiovascular disease: The ARIC Study. J Am Heart Assoc 2018;7:e009683.

6. Gao C, Wang Y, Gu X, et al. Association between cardiac injury and mortality in hospitalized patients infected with avian influenza A (H7N9) virus. Crit Care Med 2020;48:451-8.

7. Corrales-Medina VF, Musher DM, Wells GA, et al. Cardiac complications in patients with community-acquired pneumonia: incidence, timing, risk factors, and association with short-term mortality. Circulation 2012;125:773-81.

8. Lu R, Zhao X, Li J, et al. Genomic characterisation and epidemiology of 2019 novel coronavirus: implications for virus origins and receptor binding. Lancet 2020;395:565-74.

9. Li W, Moore MJ, Vasilieva N, et al. Angiotensin-converting enzyme 2 is a functional receptor for the SARS coronavirus. Nature 2003;426: $450-4$. 
10. Hoffmann M, Kleine-Weber H, Schroeder S, et al. SARS-CoV-2 cell entry depends on ACE2 and TMPRSS2 and is blocked by a clinically proven protease inhibitor. Cell 2020;181:271-280.e278.

11. Hamming I, Timens W, Bulthuis ML, et al. Tissue distribution of ACE2 protein, the functional receptor for SARS coronavirus. A first step in understanding SARS pathogenesis. J Pathol 2004;203:631-7.

12. Santos RA. Angiotensin-(1-7). Hypertension 2014;63:1138-47.

13. Zhou F, Yu T, Du R, et al. Clinical course and risk factors for mortality of adult inpatients with COVID-19 in Wuhan, China: a retrospective cohort study. Lancet 2020;395:1054-62.

14. Wang D, Hu B, Hu C, et al. Clinical characteristics of 138 hospitalized patients with 2019 novel coronavirus-infected pneumonia in Wuhan, China. JAMA 2020;323:1061-9.

15. Ruan Q, Yang K, Wang W, Jiang L, Song J. Clinical predictors of mortality due to COVID-19 based on an analysis of data of 150 patients from Wuhan, China. Intensive Care Med 2020;46:1294-7.

16. Tavazzi G, Pellegrini C, Maurelli M, et al. Myocardial localization of coronavirus in COVID-19 cardiogenic shock. Eur J Heart Fail 2020;22: 911-5.

17. Zheng YY, Ma YT, Zhang JY, Xie X. COVID-19 and the cardiovascular system. Nat Rev Cardiol 2020;17:259-60.

18. Kubasiak LA, Hernandez OM, Bishopric NH, Webster KA. Hypoxia and acidosis activate cardiac myocyte death through the Bcl-2 family protein BNIP3. Proc Natl Acad Sci U S A 2002;99:12825-30.

19. Crackower MA, Sarao R, Oudit GY, et al. Angiotensin-converting enzyme 2 is an essential regulator of heart function. Nature 2002;417: $822-8$.

20. Tikellis C, Thomas MC. Angiotensin-converting enzyme 2 (ACE2) is a key modulator of the renin angiotensin system in health and disease. Int J Pept 2012;2012:256294.

21. Lippi G, Lavie CJ, Sanchis-Gomar F. Cardiac troponin I in patients with coronavirus disease 2019 (COVID-19): evidence from a metaanalysis. Prog Cardiovasc Dis 2020;63:390-1.

22. Wong CK, Lam CW, Wu AK, et al. Plasma inflammatory cytokines and chemokines in severe acute respiratory syndrome. Clin Exp Immunol 2004;136:95-103.

23. Xu Z, Shi L, Wang Y, et al. Pathological findings of COVID-19 associated with acute respiratory distress syndrome. Lancet Respir Med 2020;8:420-2.

24. Onder G, Rezza G, Brusaferro S. Case-fatality rate and characteristics of patients dying in relation to COVID-19 in Italy. JAMA 2020;323: $1775-6$.

25. Wang Z, Chen Z, Zhang L, et al. Status of hypertension in China: results from the China hypertension survey, 2012-2015. Circulation 2018;137:2344-56.

26. Wang L, Gao P, Zhang M, et al. Prevalence and ethnic pattern of diabetes and prediabetes in China in 2013. JAMA 2017;317:2515-23.

27. Zhao D, Liu J, Wang M, Zhang X, Zhou M. Epidemiology of cardiovascular disease in China: current features and implications. Nat Rev Cardiol 2019;16:203-12.

28. Zhou M, Wang H, Zeng X, et al. Mortality, morbidity, and risk factors in China and its provinces, 1990-2017: a systematic analysis for the Global Burden of Disease Study 2017. Lancet 2019;394:1145-58.
29. Wang $\mathrm{M}$, Luo $\mathrm{X}, \mathrm{Xu} \mathrm{S}$, et al. Trends in smoking prevalence and implication for chronic diseases in China: serial national cross-sectional surveys from 2003 to 2013. Lancet Respir Med 2019;7:35-45.

30. Guan WJ, Ni ZY, Hu Y, et al. Clinical characteristics of coronavirus disease 2019 in China. N Engl J Med 2020;382:1708-20.

31. Chen N, Zhou M, Dong X, et al. Epidemiological and clinical characteristics of 99 cases of 2019 novel coronavirus pneumonia in Wuhan, China: a descriptive study. Lancet 2020;395:507-13.

32. Zhang JJ, Dong X, Cao YY, et al. Clinical characteristics of 140 patients infected with SARS-CoV-2 in Wuhan, China. Allergy 2020;75: $1730-41$.

33. Perez-Saez J, Lauer SA, Kaiser L, et al. Serology-informed estimates of SARS-CoV-2 infection fatality risk in Geneva, Switzerland [e-pub ahead of print]. Lancet Infect Dis, https://doi.org/10.1016/s1473-3099(20) 30584-3. Accessed September 2, 2020.

34. Wu C, Chen X, Cai Y, et al. Risk factors associated with acute respiratory distress syndrome and death in patients with coronavirus disease 2019 pneumonia in Wuhan, China. JAMA Intern Med 2020;180:934-43.

35. Fang L, Karakiulakis G, Roth M. Are patients with hypertension and diabetes mellitus at increased risk for COVID-19 infection? Lancet Respir Med 2020;8:e21.

36. American College of Cardiology. COVID-19 clinical guidance for the cardiovascular care team. Available at: https://www.acc.org// /media/ Non-Clinical/Files-PDFs-Excel-MS-Word-etc/2020/02/S20028-ACCClinical-Bulletin-Coronavirus.pdf. Accessed March 19, 2020.

37. College of Health. Characteristics of COVID-19 patients dying in Italy. Available at: https://www.epicentro.iss.it/en/coronavirus/bollettino/ Report-COVID-2019_14_May_2020.pdf. Accessed May 18, 2020.

38. Grasselli G, Zangrillo A, Zanella A, et al. Baseline characteristics and outcomes of 1591 patients infected with SARS-CoV-2 admitted to ICUs of the Lombardy Region. Italy. JAMA 2020;323:1574-81.

39. Arentz M, Yim E, Klaff L, et al. Characteristics and outcomes of 21 critically ill patients with COVID-19 in Washington State. JAMA 2020;323:1612-4.

40. Goyal P, Choi JJ, Pinheiro LC, et al. Clinical characteristics of covid-19 in New York City. N Engl J Med 2020;382:2372-4.

41. Myers LC, Parodi SM, Escobar GJ, Liu VX. Characteristics of hospitalized adults with COVID-19 in an integrated health care system in California. JAMA 2020;323:2195-8.

42. Richardson S, Hirsch JS, Narasimhan M, et al. Presenting characteristics, comorbidities, and outcomes among 5700 patients hospitalized with COVID-19 in the New York City area. JAMA 2020;323:2052-9.

43. Yang X, Yu Y, Xu J, et al. Clinical course and outcomes of critically ill patients with SARS-CoV-2 pneumonia in Wuhan, China: a singlecentered, retrospective, observational study. Lancet Respir Med 2020;8:475-81.

44. Guo T, Fan Y, Chen M, et al. Cardiovascular implications of fatal outcomes of patients with coronavirus disease 2019 (COVID-19). JAMA Cardiol 2020;5:811-8.

45. Shi S, Qin M, Shen B, et al. Association of cardiac injury with mortality in hospitalized patients with COVID-19 in Wuhan, China. JAMA Cardiol 2020;5:802-10.

46. Wei JF, Huang FY, Xiong TY, et al. Acute myocardial injury is common in patients with covid-19 and impairs their prognosis. Heart 2020;106:1154-9. 
47. Feldstein LR, Rose EB, Horwitz SM, et al. Multisystem inflammatory syndrome in U.S. children and adolescents. N Engl J Med 2020;383: $334-46$.

48. Dufort EM, Koumans EH, Chow EJ, et al. Multisystem inflammatory syndrome in children in New York State. N Engl J Med 2020;383: $347-58$.

49. Yu CM, Wong RS, Wu EB, et al. Cardiovascular complications of severe acute respiratory syndrome. Postgrad Med J 2006;82:140-4.

50. Al-Abdely HM, Midgley CM, Alkhamis AM, et al. Middle East respiratory syndrome coronavirus infection dynamics and antibody responses among clinically diverse patients, Saudi Arabia. Emerg Infect Dis 2019;25:753-66.

51. Peiris JS, Chu CM, Cheng VC, et al. Clinical progression and viral load in a community outbreak of coronavirus-associated SARS pneumonia: a prospective study. Lancet 2003;361:1767-72.

52. Kuba K, Imai $Y$, Rao S, et al. A crucial role of angiotensin converting enzyme 2 (ACE2) in SARS coronavirus-induced lung injury. Nat Med 2005;11:875-9.

53. Castiglione V, Chiriacò M, Emdin M, Taddei S, Vergaro G. Statin therapy in COVID-19 infection. Eur Heart J Cardiovasc Pharmacother 2020;6:258-9.

54. De Loecker I, Preiser JC. Statins in the critically ill. Ann Intensive Care 2012;2:19.

55. Makris D, Manoulakas E, Komnos A, et al. Effect of pravastatin on the frequency of ventilator-associated pneumonia and on intensive care unit mortality: open-label, randomized study. Crit Care Med 2011;39: 2440-6.

56. Papazian L, Roch A, Charles PE, et al. Effect of statin therapy on mortality in patients with ventilator-associated pneumonia: a randomized clinical trial. JAMA 2013;310:1692-700.

57. Yuan X, Deng Y, Guo X, et al. Atorvastatin attenuates myocardial remodeling induced by chronic intermittent hypoxia in rats: partly involvement of TLR-4/MYD88 pathway. Biochem Biophys Res Commun 2014;446:292-7.

58. Yuan S. Statins may decrease the fatality rate of Middle East respiratory syndrome infection. mBio 2015;6:e1120.

59. Diaz JH. Hypothesis: angiotensin-converting enzyme inhibitors and angiotensin receptor blockers may increase the risk of severe COVID19. J Travel Med 2020;27. taaa041.

60. Esler M, Esler D. Can angiotensin receptor-blocking drugs perhaps be harmful in the COVID-19 pandemic? J Hypertens 2020;38: $781-2$.

61. Ferrario CM, Jessup J, Chappell MC, et al. Effect of angiotensinconverting enzyme inhibition and angiotensin II receptor blockers on cardiac angiotensin-converting enzyme 2. Circulation 2005;111: 2605-10.

62. Ishiyama Y, Gallagher PE, Averill DB, et al. Upregulation of angiotensin-converting enzyme 2 after myocardial infarction by blockade of angiotensin II receptors. Hypertension 2004;43:970-6.

63. Jia H. Pulmonary angiotensin-converting enzyme 2 (ACE2) and inflammatory lung disease. Shock 2016;46:239-48.

64. Vaduganathan M, Vardeny $\mathrm{O}$, Michel $\mathrm{T}$, et al. Renin-angiotensinaldosterone system inhibitors in patients with covid-19. N Engl J Med 2020;382:1653-9.

65. American Heart Association/Heart Failure Society of America/American College of Cardiology. Patients taking ACE-i and ARBs who contract
COVID-19 should continue treatment, unless otherwise advised by their physician. Available at: https://newsroom.heart.org/news/patientstaking-ace-i-and-arbs-who-contract-covid-19-should-continue-treatmen t-unless-otherwise-advised-by-their-physician?utm_campaign=sciencen ews19-20\&utm_source=science-news\&utm_medium $=$ phd-link\&utm _content=phd03-17-20. Accessed March 18, 2020.

66. Canadian Cardiovascular Society. Guidance from the CCS Covid-19 Rapid Response Team. UPDATED - COVID-19 and concerns regarding use of cardiovascular medications, including ACEi/ARB/ ARNi, low-dose ASA and non-steroidal anti-inflammatory drugs (NSAIDS). Available at: https://www.ccs.ca/images/Images_2020/ CCS_CHFS_Update_COVID_CV_medications_Mar20.pdf. Accessed March 24, 2020.

67. European Society of Cardiology. Position statement of the ESC Council on Hypertension on ACE-inhibitors and angiotensin receptor blockers. Available at: https://www.escardio.org/Councils/Council-onHypertension-(CHT)/News/position-statement-of-the-esc-council-on-h ypertension-on-ace-inhibitors-and-ang. Accessed March 24, 2020.

68. Khan N. Hypertension Canada's statement on: hypertension, ACEinhibitors and angiotensin receptor blockers and COVID-19. Available at: https://hypertension.ca/wp-content/uploads/2020/03/ 2020-30-15-Hypertension-Canada-Statement-on-COVID-19-ACEi-A RB.pdf. Accessed March 24, 2020.

69. European Society of Hypertension. Statement of the European Society of Hypertension (ESH) on hypertension, renin-angiotensin system (RAS) blockers and COVID-19. Available at: https://www.eshonline. org/esh-content/uploads/2020/06/Statement-ESH-on-Hypertension-R AS-Blockers-and-COVID-19-Update-April-15-2020.pdf. Accessed May 6, 2020.

70. International Society of Hypertension. A statement from the International Society of Hypertension on COVID-19. Available at: https://ishworld.com/news/a/A-statement-from-the-International-Society-of-Hype rtension-on-COVID-19/. Accessed March 24, 2020.

71. Li J, Wang X, Chen J, Zhang H, Deng A. Association of reninangiotensin system inhibitors with severity or risk of death in patients with hypertension hospitalized for coronavirus disease 2019 (COVID19) infection in Wuhan, China. JAMA Cardiol 2020;5:825-30.

72. Mancia G, Rea F, Ludergnani M, Apolone G, Corrao G. Reninangiotensin-aldosterone system blockers and the risk of covid-19. N Engl J Med 2020;382:2431-40.

73. Reynolds HR, Adhikari S, Pulgarin C, et al. Renin-angiotensin-aldosterone system inhibitors and risk of covid-19. N Engl J Med 2020;382: 2441-8.

74. Mehta N, Kalra A, Nowacki AS, et al. Association of use of angiotensinconverting enzyme inhibitors and angiotensin ii receptor blockers with testing positive for coronavirus disease 2019 (COVID-19). JAMA Cardiol 2020;15:1020-6.

75. de Abajo FJ, Rodríguez-Martín S, Lerma V, et al. Use of reninangiotensin-aldosterone system inhibitors and risk of COVID-19 requiring admission to hospital: a case-population study. Lancet 2020;395:1705-14.

76. US National Library of Medicine. Stopping ACE-inhibitors in COVID19 (ACEI-COVID). Available at: https://clinicaltrials.gov/ct2/show/ NCT04353596. Accessed May 5, 2020.

77. US National Library of Medicine. Elimination or prolongation of ACE inhibitors and ARB in coronavirus disease 2019 (REPLACECOVID). Available at: https://clinicaltrials.gov/ct2/show/NCT0 4338009. Accessed May 5, 2020. 
78. University of Liverpool. Prescribing Resources: Detailed recommendations for interactions with experimental COVID-19 therapies. Available at: https://www.covid19-druginteractions.org/prescribing-resources. Accessed July 21, 2020.

79. Liu J, Cao R, Xu M, et al. Hydroxychloroquine, a less toxic derivative of chloroquine, is effective in inhibiting SARS-CoV-2 infection in vitro. Cell Discovery 2020;6:16.

80. Page RL 2nd, O'Bryant CL, Cheng D, et al. Drugs that may cause or exacerbate heart failure: a scientific statement from the American Heart Association. Circulation 2016;134:e32-69.

81. Geleris J, Sun Y, Platt J, et al. Observational study of hydroxychloroquine in hospitalized patients with covid-19. N Engl J Med 2020;382:2411-8.

82. Cavalcanti AB, Zampieri FG, Rosa RG, et al. Hydroxychloroquine with or without azithromycin in mild-to-moderate covid-19. N Engl J Med 2020;382:2041-52.

83. Gao J, Tian Z, Yang X. Breakthrough: chloroquine phosphate has shown apparent efficacy in treatment of COVID-19 associated pneumonia in clinical studies. Biosci Trends 2020;14:72-3.

84. Tonnesmann E, Kandolf R, Lewalter T. Chloroquine cardiomyopathy - a review of the literature. Immunopharmacol Immunotoxicol 2013;35:434-42.

85. Tonnesmann E, Stroehmann I, Kandolf R, et al. Cardiomyopathy caused by longterm treatment with chloroquine: a rare disease, or a rare diagnosis? J Rheumatol 2012;39:1099-103.

86. Borba MGS, Val FFA, Sampaio VS, et al. Effect of high vs low doses of chloroquine diphosphate as adjunctive therapy for patients hospitalized with severe acute respiratory syndrome coronavirus 2 (SARS-CoV-2) infection: a randomized clinical trial. JAMA Netw Open 2020;3: e208857.

87. Chorin E, Dai M, Shulman E, et al. The QT interval in patients with COVID-19 treated with hydroxychloroquine and azithromycin. Nat Med 2020;26:808-9.

88. Mercuro NJ, Yen CF, Shim DJ, et al. Risk of QT interval prolongation associated with use of hydroxychloroquine with or without concomitant azithromycin among hospitalized patients testing positive for coronavirus disease 2019 (COVID-19). JAMA Cardiol 2020;5:1036-41.

89. Bessière F, Roccia $\mathrm{H}$, Delinière $\mathrm{A}$, et al. Assessment of QT intervals in a case series of patients with coronavirus disease 2019 (COVID-19) infection treated with hydroxychloroquine alone or in combination with azithromycin in an intensive care. JAMA Cardiol 2020;15:1067-9.

90. Fernandes FM, Silva EP, Martins RR, Oliveira AG. QTc interval prolongation in critically ill patients: prevalence, risk factors and associated medications. PLoS One 2018;13:e0199028.

91. Wang M, Cao R, Zhang L, et al. Remdesivir and chloroquine effectively inhibit the recently emerged novel coronavirus (2019-nCoV) in vitro. Cell Res 2020;30:269-71.

92. Sanders JM, Monogue ML, Jodlowski TZ, Cutrell JB. Pharmacologic treatments for coronavirus disease 2019 (COVID-19): a review. JAMA 2020;323:1824-36.

93. National Institutes of Health. NIH clinical trial shows Remdesivir accelerates recovery from advanced COVID-19. Available at: https:// www.nih.gov/news-events/news-releases/nih-clinical-trial-shows-remde sivir-accelerates-recovery-advanced-covid-19. Accessed May 6, 2020.

94. Wang Y, Zhang D, Du G, et al. Remdesivir in adults with severe COVID-19: a randomised, double-blind, placebo-controlled, multicentre trial. Lancet 2020;395:1569-78.
95. RECOVERY Collaborative Group, Horby P, Lim WS, et al. Dexamethasone in hospitalized patients with covid-19 - preliminary report [e-pub ahead of print]. N Engl J Med, https://doi.org/10.1056/ NEJMoa2021436, accessed December 17, 2020.

96. Cao B, Wang Y, Wen D, et al. A trial of lopinavir-ritonavir in adults hospitalized with severe covid-19. N Engl J Med 2020;382:1787-99.

97. Liu K, Fang YY, Deng Y, et al. Clinical characteristics of novel coronavirus cases in tertiary hospitals in Hubei Province. Chin Med J (Engl) 2020;133:1025-31.

98. He J, Wu B, Chen Y, et al. Characteristic electrocardiographic manifestations in patients with COVID-19. Can J Cardiol 2020;36. 966.e1-4.

99. Minhas AS, Scheel P, Garibaldi B, et al. Takotsubo syndrome in the setting of COVID-19. JACC Case Rep 2020;2:1321-5.

100. Oxley TJ, Mocco J, Majidi S, et al. Large-vessel stroke as a presenting feature of covid-19 in the young. N Engl J Med 2020;382:e60.

101. Connors JM, Levy JH. COVID-19 and its implications for thrombosis and anticoagulation. Blood 2020;135:2033-40.

102. Thachil J, Tang N, Gando S, et al. ISTH interim guidance on recognition and management of coagulopathy in COVID-19. J Thromb Haemost 2020;18:1023-6.

103. Tang N, Bai H, Chen X, et al. Anticoagulant treatment is associated with decreased mortality in severe coronavirus disease 2019 patients with coagulopathy. J Thromb Haemost 2020;18:1094-9.

104. Paranjpe I, Fuster V, Lala A, et al. Association of treatment dose anticoagulation with in-hospital survival among hospitalized patients with COVID-19. J Am Coll Cardiol 2020;76:122-4.

105. Chen C, Zhou Y, Wang DW. SARS-CoV-2: a potential novel etiology of fulminant myocarditis. Herz 2020;45:230-2.

106. Kociol RD, Cooper LT, Fang JC, et al. Recognition and initial management of fulminant myocarditis: a scientific statement from the American Heart Association. Circulation 2020;141:e69-92.

107. Inciardi RM, Lupi L, Zaccone G, et al. Cardiac involvement in a patient with coronavirus disease 2019 (COVID-19). JAMA Cardiol 2020;5: 819-24.

108. Dabbagh MF, Aurora L, D'Souza P, et al. Cardiac tamponade secondary to COVID-19. JACC Case Rep 2020;2:1326-30.

109. Hua A, O'Gallagher K, Sado D, Byrne J. Life-threatening cardiac tamponade complicating myo-pericarditis in COVID-19. Eur Heart J 2020;41:2130.

110. Chow J, Alhussaini A, Calvillo-Argüelles O, Billia F, Luk A. Cardiovascular collapse in COVID-19 infection: the role of venoarterial extracorporeal membrane oxygenation (VA-ECMO). CJC Open 2020;2:273-7.

111. Henry BM. COVID-19, ECMO, and lymphopenia: a word of caution. Lancet Respir Med 2020;8:e24.

112. MacLaren G, Fisher D, Brodie D. Preparing for the most critically ill patients with COVID-19: the potential role of extracorporeal membrane oxygenation. JAMA 2020;323:1245-6.

113. Rita R. Global effort to collect data on ventilated patients with COVID19. JAMA 2020;323:2233-4.

114. Welt FGP, Shah PB, Aronow HD, et al. Catheterization laboratory considerations during the coronavirus (COVID-19) pandemic: from ACC's Interventional Council and SCAI. J Am Coll Cardiol 2020;75: 2372-5. 
115. Zeng J, Huang J, Pan L. How to balance acute myocardial infarction and COVID-19: the protocols from Sichuan Provincial People's Hospital. Intensive Care Med 2020;46:1111-3.

116. Bangalore S, Sharma A, Slotwiner A, et al. ST-segment elevation in patients with covid-19-a case series. N Engl J Med 2020;382: 2478-80.

117. Tam CF, Cheung KS, Lam S, et al. Impact of coronavirus disease 2019 (COVID-19) outbreak on ST-segment-elevation myocardial infarction care in Hong Kong, China. Circ Cardiovasc Qual Outcomes 2020;13: e006631.

118. Bauchner H, Golub RM, Zylke J. Editorial concern-possible reporting of the same patients with COVID-19 in different reports. JAMA 2020;323:1256.

119. Xie J, Tong Z, Guan X, Du B, Qiu H. Clinical characteristics of patients who died of coronavirus disease 2019 in China. JAMA Netw Open 2020;3:e205619. 